Revista Aspas

ppgac - USP

Artigo

\title{
ROTAS INTERLIGADAS: CARTOGRAFIAS DE UMA ARTISTA INQUIETA
}

\author{
INTERCONNECTED ROUTES: AN UNSETTLED ARTIST'S \\ CARTOGRAPHY
}

RUTAS INTERCONECTADAS: CARTOGRAFÍAS DE UNA ARTISTA INQUIETA

\author{
Maria Fernanda Vomero
}

Maria Fernanda Vomero

Mestre em Artes Cênicas pela Universidade de São Paulo 


\section{Resumo}

Este artigo reúne anotações e reflexões sobre o entrelaçamento de percursos criativos - provocação artística, curadoria de ações pedagógicas e pesquisa acadêmica - e os aprendizados advindos da análise de processos cênicos por meio da abordagem cartográfica, uma metodologia que contempla, além do fenômeno estudado, a experiência e o próprio pensar sobre a produção de conhecimento.

Palavras-chave: Teatro, Processo cênico, Curadoria, Cartografia, Documentos.

\section{Abstract}

This article gathers notes and reflections on the interlacing of creative courses - artistic provocations, curatorship of pedagogical actions and academic research - and the learning arising from the analysis of scenic processes by means of the cartographic approach, a methodology that encompasses, beyond the phenomenon studied, the experience and the thinking itself about knowledge production.

Keywords: Theatre, Scenic process, Curatorship, Cartography, Documents.

\section{Resumen}

En este texto se presentan notas y reflexiones sobre el entramado de recorridos creativos -provocación artística, comisaría de actividades pedagógicas e investigación académica- y el aprendizaje a partir del análisis de los procesos escénicos desde el abordaje cartográfico, y reúne en una metodología, además del fenómeno estudiado, la experiencia y el propio pensar sobre la producción del conocimiento.

Palabras clave: Teatro, Proceso escénico, Curaduría, Cartografía, Documentos. 
Caminante, son tus huellas el camino y nada más;

Caminante, no hay camino, se hace camino al andar. Antonio Machado, Proverbios y Cantares

\section{Introdução}

Quando a Companhia de Teatro Heliópolis me convidou a contribuir para o projeto Microviolências e suas naturalizações, naquele momento em elaboração - e, posteriormente, contemplado pela 28ª edição do Programa Municipal de Fomento ao Teatro para a cidade de São Paulo -, refletimos sobre como se daria minha participação. Desde o fim de 2014 eu já vinha acompanhando, na condição de provocadora e comentadora, os processos cênicos da companhia, cujos resultados foram as peças $A$ inocência do que (não) sei e Medo. Levava alguns temas e textos para a discussão, assistia às cenas já prontas, propunha reflexões relacionadas ao que assistia. Para o novo projeto, minha atuação seria não só oficializada como também formalizada. Depois de profícuas conversas com o diretor Miguel Rocha, cheguei a uma proposta: eu me responsabilizaria pela partilha teórica com os artistas sobre violência e tópicos afins, tanto por meio de encontros semanais quanto pela mediação de um ciclo de debates do qual também seria curadora. Além disso, em consonância com minha área de pesquisa na universidade - pedagogia do teatro -, levaríamos nossos questionamentos para a cena, usando improvisações e jogos teatrais e apostando no que Pupo (2015) afirma acerca das relações entre teatro e educação: "É assim que podemos chegar àquilo que almejamos: tornar possível a um grupo a articulação de sua visão de mundo e dos seus desejos através de um discurso teatral".

Era um campo de atuação totalmente novo para mim - embora não tão inesperado -, uma vez que, naquele momento, minhas trajetórias profissional e acadêmica pareciam convergir para um intenso diálogo entre pesquisa, produção crítica e criação artística. Em 2015 havia começado meu percurso no Programa de Pós-Graduação em Artes Cênicas da Universidade de São Paulo, depois de alguns anos investigando informalmente o tema de minha 
dissertação: teatro e direitos humanos na Palestina ${ }^{1}$. Além disso, assumi a curadoria do eixo Ações Pedagógicas, na Mostra Internacional de Teatro de São Paulo (MITsp), função que mantenho até o momento. O fato é que, paralelamente ao estudo acadêmico dos procedimentos criativos e pedagógicos de um grupo teatral palestino, estive envolvida com o processo cênico da Companhia de Teatro Heliópolis e pude acompanhar, graças ao trabalho como curadora de atividades formativas nos últimos três anos, métodos e práticas de artistas convidados de um festival internacional.

Minha opção metodológica ao longo do mestrado foi, desde o princípio, a abordagem cartográfica (PASSOS et al., 2009), que privilegia o plano da experiência, conecta teoria, vivência e prática, e ressalta o caráter processual da pesquisa, contemplando os efeitos gerados pela própria investigação no caso estudado, no pesquisador e na produção do conhecimento. Assim, o que emerge desse percurso não é um "saber sobre" distanciado e devidamente asséptico, mas um "saber com". Tal metodologia tem se revelado adequada também para compreender os saberes que advêm do intercâmbio criativo propiciado pelos encontros teórico-práticos com os artistas da Companhia de Teatro Heliópolis e pelas residências artísticas, oficinas e encontros formativos oferecidos nas edições da Mostra Internacional de Teatro.

\section{Rota I: artista-provocadora}

A Companhia de Teatro Heliópolis surgiu no ano 2000, pela iniciativa de Miguel Rocha, com a reunião de jovens da favela homônima a fim de montar um espetáculo baseado no romance $A$ queda para o alto, de Sandra Mara Herzer (ou Anderson Herzer, nome que passou a adotar). Com apoio da União de Núcleos e Associações de Moradores de Heliópolis e Região (UNAS) e patrocínio da Eletropaulo, a peça estreou em novembro daquele ano e chegou a ser apresentada no Teatro Oficina, a convite do diretor José Celso Martinez Corrêa, com a presença do então senador Eduardo Suplicy.

1. Mestrado defendido em outubro de 2017 sob orientação de Maria Lúcia Pupo, com a dissertação Teatro e direitos humanos: ética e estética como forma de resistência, sobre o grupo e centro cultural Teatro da Liberdade, no campo de refugiados de Jenin, norte da Cisjordânia. 
Entre 2001 e 2002 circulou pela capital e pelo interior de São Paulo, e, com o apoio da Petrobras, passou por outras sete capitais do Brasil.

Depois vieram Coração de vidro (2004) e Os meninos do Brasil (2007). Entre 2008 e 2009, com o patrocínio da Petrobras, foi iniciado o projeto Arte e Cidadania em Heliópolis, que visava proporcionar o aprimoramento da experiência artística e o aprofundamento da pesquisa estética tanto dos artistas da companhia quanto dos colaboradores. O projeto constituiu-se de quatro fases - formação, pesquisa, criação e apresentação - com encontros diários e aulas dadas por diversos profissionais convidados. O Arte e Cidadania teve três módulos e cada um resultou em um espetáculo: $O$ dia em que Túlio descobriu a África (2009), remontado em 2012 e vencedor do Prêmio da Cooperativa Paulista de Teatro 2012 na categoria ocupação de espaço; Nordeste/Heliópolis/Brasil - primeiro ato (2011) e Um lugar ao sol (2013). Durante o período, fora do projeto, a companhia montou a peça $E u$ quero sexo... será que vai rolar? (2010).

Em 2015, a Companhia de Teatro Heliópolis foi contemplada pela 25a edição do Programa Municipal de Fomento ao Teatro para a Cidade de São Paulo com o projeto Onde o percurso começa? Princípios de identidade e alteridade no campo da educação, que resultou na montagem $A$ inocência do que eu (não) sei. No ano seguinte, estreou o espetáculo Medo, inspirado nos ataques do Primeiro Comando da Capital (PCC) em São Paulo em 2006. E então veio o aceite, pela 28 ${ }^{\text {a }}$ Edição do Programa Municipal de Fomento ao Teatro, do projeto Microviolências e suas naturalizações, cujo intenso processo de criação - ao longo de quase um ano - gerou a peça Sutil violento, com três meses de temporada gratuita na sede da companhia, a Casa Maria José de Carvalho, no bairro do Ipiranga, vizinho a Heliópolis.

É interessante notar que os diversos projetos desenvolvidos pela Companhia de Teatro Heliópolis sempre contemplaram a investigação aprofundada de temas e linguagens, além do crescimento pessoal de seus participantes. A depuração estética nunca esteve dissociada do aprimoramento crítico e de um alargamento da percepção sensível. Por isso, minha contribuição encontrou ambiente propício para a experimentação; as tentativas sempre levavam a um aprendizado conjunto. Tornamo-nos, assim, parceiros de criação. 
Os encontros realizados durante a etapa da provocação teórico-artística tiveram como premissa o estudo de textos previamente escolhidos, debates em grupo e o exercício cênico por meio de jogos teatrais e de improvisações. As leituras incluíram tanto artigos acadêmicos sobre temas relacionados à violência quanto peças, poemas, contos e crônicas jornalísticas. Os conceitos principais dos textos trabalhados eram usados como base para chegarmos às ações-síntese levadas para a cena. Adotamos a metodologia do protocoIo² (KOUDELA, 2001), que batizamos de "diário de bordo", para registro das atividades semanais e como ferramenta de reflexão contínua sobre as experiências vividas pelo grupo. A cada semana, um dos artistas era responsável pela leitura de seu "texto" a respeito do encontro anterior - texto entre aspas porque a forma aberta do protocolo permitiu que os intérpretes experimentassem modos poéticos de partilhar suas descobertas e inquietações. Tal procedimento metodológico revelou-se essencial, na medida que materializou, de certa maneira, as significações atribuídas pelos artistas ao processo e os saberes produzidos durante aquele período.

Se minhas proposições influenciavam as criações cênicas dos atores e atrizes, seus protocolos igualmente me instigavam a explorar mais ou menos certos elementos, investigar novos caminhos estéticos e revisar, com frequência, meu plano de trabalho. Não só as vivências em si inspiravam as propostas do encontro seguinte, a percepção de cada artista, externada em seu relato apresentado ao grupo, contribuía para a formulação das atividades. 0 amadurecimento pessoal e artístico não estava acontecendo apenas com os intérpretes da companhia, eu também o vivenciava do meu lugar de provocadora. Concordo quando Maria Lúcia Pupo (2015, p. 21) afirma que

Fazemos referência a uma prática artística plena, sem concessões, tecida a uma ação educativa, social, portanto sempre de cunho direta ou indiretamente político. Temos muito a ganhar quando nossa prática derruba barreiras que tendem ao congelamento. Temos muito a ganhar quando focalizamos nossos esforços em um processo teatral que traz em seu bojo, indissociável, uma ampliação da consciência de quem o vive.

2. Protocolos podem ser definidos como registros apresentados no início de cada nova sessão de trabalho sobre as atividades vivenciadas no encontro anterior. 
Arte do efêmero e da presença, o teatro depara-se sempre com o desafio do registro e da documentação de seus processos e procedimentos cênicos. Por isso, além do registro visual das etapas de criação - como captar esse "invisível" que o teatro exibe e deixa ver ${ }^{3}-$, Miguel Rocha, diretor da Companhia de Teatro Heliópolis, busca, em todos os projetos, criar um programa do espetáculo que rastreie tanto quanto possível as dimensões palpáveis do percurso criativo. Assumi a responsabilidade pela elaboração do programa de Sutil violento ao lado de Miguel; refletimos sobre como a palavra escrita poderia dar conta daquilo que todos havíamos experimentado até o espetáculo ficar pronto. Os elementos gráficos - como a cor dominante (vermelho), o maniqueísmo expresso por meio do dualismo cromático etc. - também poderiam contribuir para a "compreensão semiótica", digamos. Além das seções de praxe (sinopse, ficha técnica, serviço), optamos por um texto do diretor a respeito do processo, intitulado A busca coletiva por nosso próprio discurso; alguns breves testemunhos de cada um dos participantes (entre atores e atrizes, equipe técnica, orientadores e provocadores), sob a rubrica Percurso; e três ensaios curtos sobre o tema das violências naturalizadas, cujos autores foram Alexandre Mate, orientador da pesquisa sobre o épico, o dramaturgo Evill Rebouças e eu.

Em minha pesquisa acadêmica, quando estudava a trajetória de um grupo teatral e de um centro cultural palestino estabelecido em 2006 a fim de compreender suas práticas pedagógicas e produções artísticas atuais, precisei recorrer a registros e documentos como aqueles produzidos para Sutil violento e outros mais, como fotos, vídeos, sinopses, críticas e reportagens. Também realizei entrevistas com artistas e outros envolvidos, que, por meio do relato oral, partilhavam impressões e experiências retidas na memória. Parece-me fundamental - e inevitável - que a pesquisa em artes cênicas contemple tais fontes.

3. Cf. Guénoun (2003, p. 46). 


\section{Rota II: artista-curadora}

Criada pelo encenador Antonio Araújo, diretor do Teatro da Vertigem e professor do departamento de Artes Cênicas da Universidade de São Paulo (USP), e pelo ator e produtor Guilherme Marques, diretor geral do Centro Internacional de Teatro Ecum, a MITsp reúne anualmente companhias e artistas locais e estrangeiros, revelando o que tem sido realizado na cena contemporânea mundial. Desde o início o evento procurou retomar a ambição que guiou os históricos festivais de teatro organizados pela atriz e produtora Ruth Escobar entre 1974 e 1999: trazer à capital paulista a produção cênica de destaque internacional. A MITsp constitui-se sobre três eixos: a mostra de espetáculos propriamente dita; as iniciativas - agrupadas sob o nome Olhares Críticos - de debate e reflexão; e as atividades de intercâmbio artístico, isto é, as Ações Pedagógicas.

Que ferramentas metodológicas me permitiriam examinar de modo crítico a consolidação e o amadurecimento do eixo Ações Pedagógicas, considerando que sou parte envolvida e que não há - ainda e infelizmente - um olhar analítico externo e nem uma produção escrita a respeito? Novamente me apoio na abordagem cartográfica, tal e qual problematizada nos ensaios de Pistas do método da cartografia: pesquisa-intervenção e produção de subjetividade (PASSOS et al., 2009), por contemplar o caráter processual e inventivo do estudo e um pensamento que acompanha a construção daquilo que ele pensa, sempre atento às movimentações micropolíticas (Ibid., p. 1011). Não se trata, portanto, de representar um objeto estanque ("a oficina" ou "a residência") à moda cientificista.

Minha contribuição à MITsp começou em sua primeira edição, em 2014, quando fui convidada ao workshop intensivo (e intenso!) conduzido pelos britânicos Simon McBurney, diretor artístico da companhia Complicite, e Gareth Fry, designer sonoro. O workshop ocorreu durante quatro dias, com oito horas diárias de experimentação, e vinte participantes previamente selecionados. A ideia era que minhas anotações se tornassem uma reflexão aberta sobre a partilha criativa entre convidados internacionais e artistas locais e que constasse no catálogo da edição seguinte.

O tal artigo jamais foi publicado, mas se transformou em um dos meus suportes quando assumi a curadoria do eixo em 2015, com a proposta de não 
mais trazer um artista especificamente para um workshop, mas sim elaborar, com os encenadores e atores estrangeiros que já estariam no festival com seus espetáculos, uma série de oficinas que contemplasse todas as etapas do fazer teatral. As companhias convidadas assumiram, então, a iniciativa pedagógica como aspecto fundamental de sua participação na mostra. Tivemos número expressivo de inscritos e de participantes, e o eixo se afirmou como um espaço de encontros, trocas profícuas e criação artística. Os artistas internacionais ficaram bastante impressionados com a experiência. Contudo, o dilema reapareceu: como dar conta - para estudo futuro - da dimensão sensível e das conquistas no campo simbólico alcançadas em cada oficina, aula magistral ou acompanhamento de processo? Os relatórios registraram os números finais da mostra, sem espaço para digressões de ordem subjetiva. E o balanço crítico, publicado em jornais e blogs que acompanharam o festival, nem menção fez à existência do eixo Ações Pedagógicas.

Na edição seguinte, em 2016, nosso plano foi ampliado; continuaríamos propondo às companhias que se dispusessem a oferecer uma contrapartida pedagógica, como forma também de perpetuar a experiência estética dos espetáculos apresentados na mostra, mas retomaríamos a ideia de trazer um convidado "independente" para um intercâmbio de mais fôlego: uma residência artística de três semanas, com encontros diários de pelo menos cinco horas e folga apenas aos domingos. O encenador russo Yuri Butusov, que, no ano anterior havia se apresentado com o espetáculo $A$ gaivota, retornou a São Paulo e conduziu um processo pedagógico e artístico de grande potência para nove participantes.

Como em 2015, na terceira edição acompanhei intensamente as atividades sob minha responsabilidade. Uma vez mais a experiência me afetou de modo muito positivo, e não só por conhecer um pouco mais, na prática, os métodos e a abordagem criativa dos artistas convidados, mas também pelo comprometimento e pela resposta inventiva dos participantes. Oficinas e residências artísticas são ambientes de encontro e elaboração de saberes, possibilitam a experiência concreta de formulação e vivência de um pensamento artístico que engaja o corpo e se efetiva pela presença, pela materialidade, por efeitos que ultrapassam 0 ato racional e interpretativo ${ }^{4}$.

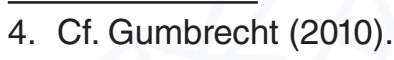


No contexto específico da Mostra Internacional de Teatro, o conjunto das ações pedagógicas tem constituído um discurso teatral e também político sobre o fazer artístico.

Em 2017, considerando as abordagens contempladas pela curadoria dos espetáculos, a cargo de Antônio Araújo, também diretor artístico da mostra, e o tema geral do festival - resistência, em resposta ao momento político brasileiro -, elaboramos uma proposta pedagógica que permitia o diálogo entre os processos criativos dos convidados e a realidade atual do Brasil. Aos artistas estrangeiros solicitamos que não só partilhassem suas práticas, mas trabalhassem determinados aspectos urgentes do cenário nacional. Enviamos, com alguma antecedência, um breve dossiê com informações sobre o país (escravidão, ditadura, populações indígenas, genocídio negro, impeachment de Dilma Rousseff, os protestos nas ruas etc.). Além disso, convidamos para liderar a residência artística um encenador palestino, Ihab Zahdeh, que conheci durante minha pesquisa de campo na Cisjordânia, em outubro de 2016. A presença de um palestino no festival já evidenciava a perspectiva de resistência. E acolhemos também a intervenção artística do coletivo de estudantes secundaristas que se conheceu nas ocupações de escolas de 2015 e 2016, sob orientação e direção da atriz e diretora Martha Kiss Perrone.

Para inscrição nas atividades com seleção, tentamos sair do convencional pedido de "currículo e breve carta de intenção" e pedimos textos criativos e não burocráticos com base em disparadores específicos para cada iniciativa ${ }^{5}$. O resultado foi surpreendente: como os protocolos produzidos ao longo do processo cênico da Companhia de Teatro Heliópolis, recebemos respostas nos mais variados formatos e com conteúdos bastante singulares. $A$ experimentação artística, a meu ver, começou nesse movimento de escrita e criação. Esse material agora constitui uma documentação valiosa para/sobre o processo da curadoria das Ações Pedagógicas.

Finda a quarta edição, minha sensação era que havíamos - a equipe da MITsp, os artistas convidados e os participantes de todas as ações propostas - conseguido formular, por meio da experiência, um discurso sobre coletividade, criatividade e potência. Algo imensurável para os relatórios

5. Disponível em: <https://goo.gl/YdKPS9>. Acesso em: 30 out. 2017. 
quantitativos, mas perfeitamente tangível para uma "cognição ampliada, isto é, aberta ao plano dos afetos" (BARROS; KASTRUP, 2009, p. 32).

\section{Rota III: artista-pesquisadora}

Tanto o trabalho com a Companhia de Teatro Heliópolis quanto a curadoria exercida nas três últimas edições da Mostra Internacional de Teatro obviamente trouxeram importantes subsídios para minha investigação de mestrado, refinando a reflexão sobre os procedimentos metodológicos que pudessem dar conta não só da análise do percurso do grupo teatral estudado e de sua escola de teatro, mas das vivências em minhas três estadas nos territórios palestinos (duas delas, aliás, anteriores ao mestrado) e do impacto sobre minhas percepções a respeito do teatro em um contexto de ocupação colonial continuada. Tornou-se evidente que pesquisas debruçadas sobre aspectos artísticos, pedagógicos e criativos não devem se restringir ao exame de um objeto isolado de suas articulações históricas e de suas conexões com o mundo (BARROS; KASTRUP, 2009, p. 30) - e, entre essas conexões, encontra-se também o pesquisador. Como diz Rolnik (1989, p. 15-16),

\footnotetext{
Sendo tarefa do cartógrafo dar língua para afetos que pedem passagem, dele se espera basicamente que esteja mergulhado nas intensidades de seu tempo e que, atento às linguagens que encontra, devore as que the parecerem elementos possíveis para a composição das cartografias que se fazem necessárias.
}

O caráter processual é continuamente evidenciado pela mesma trajetória do trabalho, que acolhe o acaso, as fissuras e possíveis desvios de rota no meio do caminho. O acúmulo de informações não se sobrepõe ao encontro e ao diálogo, não existe roteiro fixo ou normalizado que se imponha às descobertas do trajeto. No caso das artes cênicas, a submissão à exigência de uma conclusão circunscrita aos produtos finais de um processo sugere submissão ao discurso hegemônico que se ancora convenientemente na abordagem espetacular, ou seja, a do espetáculo como indicativo de efetividade e/ ou legitimidade. Nesse caso, o "automatismo das percepções cotidianas", nas 
palavras de Pupo (2015), não é questionado ou desafiado, mas simplesmente perpetuado. A expressão corre o risco de ser silenciada pela explicação.

Para Rolnik (1989), o cartógrafo se mantém atento às estratégias de formação do desejo no campo social e à constituição de territórios existenciais, por isso, em vez de explicações, acaba por criar "pontes de linguagem", canais de interlocução sensível. Trata-se - e aqui sou eu quem propõe a reflexão - de um pesquisador que se assume também como artista e se propõe a abarcar as redes de força que cercam o fenômeno analisado e as experiências que afetam ambos (ao fenômeno e ao cartógrafo) numa construção coletiva de conhecimento: o "saber com". O percurso investigativo não deveria se traduzir apenas em relatórios ou textos regulados por regras acadêmicas; ele poderia ampliar-se para experiências de linguagem que não abortem a dinâmica da vida, o movimento permanente, a presença do corpo ou a proximidade dos outros corpos na existência social. Afinal, reitero, pesquisa também gera discurso, um discurso inevitavelmente político.

Parece-me, portanto, essencial que as cartografias, sejam originárias da criação artística ou acadêmica, combinem materialidades (textos formais ou informais, protocolos, registros em imagens, objetos-síntese, pinturas, entre outras, quase como souvenirs de viagens) e expressões sensíveis (performances, falas performáticas, palestras-performance, danças, músicas, clipes audiovisuais, cenas teatrais, rodas de conversa, jogos teatrais etc.). O percurso permanece vivo quando reverbera para além de seus fins aparentes.

No meu caso, senti necessidade de levar para a cena as reverberações das rotas que têm constituído meu percurso: descobertas trazidas pelo constante diálogo com os artistas da Companhia de Teatro Heliópolis, ressonâncias das atividades realizadas durante a quarta edição da MITsp, em especial o acompanhamento do workshop dos libaneses Lina Majdalani e Rabih Mroué, e certas constatações da pesquisa de mestrado que transcenderam a própria escrita da dissertação. Combinando preceitos acadêmicos e elementos de performatividade, em interlocução direta com espectadores, agora lanço-me à aventura da palestra-performance Poder da palavra, palavra de poder, nova rota a compor minha cartografia, modo de manter vivo o movimento dos saberes nos quais me embebedo. 
Cartografias criam novos mundos. E novos mundos permitem novas possibilidades de existência e resistência.

\section{Referências bibliográficas}

BARROS, L. P.; KASTRUP, V. Cartografar é acompanhar processos. In: PASSOS, E.; KASTRUP, V.; ESCÓSSIA, L. (org.). Pistas do método da cartografia: pesquisa-intervenção e produção de subjetividade. Porto Alegre: Sulina, 2009.

GUÉNOUN, D. A exibição das palavras: uma ideia (política) do teatro. Rio de Janeiro: Teatro do Pequeno Gesto, 2003.

GUMBRECHT, H. U. Produção de presença: o que o sentido não consegue transmitir. Rio de Janeiro: Contraponto; Editora PUC-Rio, 2010.

KOUDELA, I. D. Brecht na pós-modernidade. São Paulo: Perspectiva, 2001.

PASSOS, E. et al. Apresentação. In: (org.). Pistas do método da cartogra-

fia: pesquisa-intervenção e produção de subjetividade. Porto Alegre: Sulina, 2009. PUPO, M. L. S. B. Para alimentar o desejo de teatro. São Paulo: Hucitec, 2015.

ROLNIK, S. Cartografia sentimental: transformações contemporâneas do desejo. São Paulo: Estação Liberdade, 1989.

Recebido em 8/11/2017

Aprovado em 8/11/2017

Publicado em 3/05/2018 